\title{
Electrochemical synthesis of chitosan- zinc nanocomposites
}

\author{
Fikry M. Reicha, ${ }^{\mathrm{a},}$, Ahmed Fekri ${ }^{\mathrm{b}}$, Saad Kh. Madlool ${ }^{\mathrm{a}}$, Ahmed E. Hannora ${ }^{\mathrm{c}}$ \\ a Biological Advanced Material laboratory, Department of Physics, Faculty of Science, Mansoura University, \\ Mansoura, Egypt \\ ${ }^{\mathrm{b}}$ Chemistry Department, Faculty of Science, Mansoura University, Mansoura, Egypt \\ ${ }^{c}$ Faculty of Petroleum and Mining Engineering, Suez University, Suez, Egypt
}

Received: 25 October 2015 / Accepted: 09 November 2015

* Corresponding author (Tel:+20.50.2258767, E-mail: fikry_reicha@ mans.edu.eg)

\begin{abstract}
Chitosan-zinc complexes with different zinc content were prepared electrochemically, monitored by atomic mass spectrophotometer and characterized by FT-IR, XRD, UV and TEM. It was found that the complexes with different zinc content showed different molecular structures. Molar ratios of chitosan zinc complexes were formed depending on the duration time of electroxidation process. Complexes have been partial random crystalline, while maximum concentrated complexes exhibited complete ordered amorphous. UV radiation reduction has been used to produce chitosan zinc nanocomposite. Zinc and zinc oxide nanoparticles have been detected. The colloidal solution has been found extremely stable for more than six months at ambient atmosphere.
\end{abstract}

Keywords: Chitosan- zinc, nanocomposites, preparation, Characterization

\section{Introduction}

In the current years, nanoparticles have attracted much attention due to their individual features, which are unavailable in conventional macroscopic materials. Several studies have found biomedical applications for nanoparticles mainly as antibacterial material (Palza 2015; Sirelkhatim et al. 2015 and Navale et al. 2015), cell imaging, (Hong et al. 2011and Alhadlaq et al. 2015) drug delivery, and cancer therapy (Truonga et al. 2015 and Wang et al. 2012). In comparison to their larger counterparts, nanomaterials have unique physicochemical and biological properties (Aillona et al. 2009 and Li et al. 2015). Many properties of nanomaterials, such as size, shape, chemical composition, surface structure and charge, aggregation and agglomeration, and solubility, can greatly influence their interactions with biomolecules and cells (Jo et al. 2015 and Niki et al. 2015). Introducing or implant nano-scale fillers into polymers and simply capitalizing on the filler properties to heighten performance of the composites, this produce a class of polymer/ inorganic materials described by the term nano filled polymers. Another type of nanocomposite, 
that can be termed as "polymer / inorganic hybrids" or molecular composites is genuine nanocomposites introduces new physical properties and novel attitude that are absent in the unfilled matrices, effectively changing that nature of original polymer. One of the most important composite nowadays is zinc/chitosan nanobcomposites (Saegusa 2011 and Gong et al. 2015).

Chitosan is a most abundant nontoxic, biodegradable (Rahim et al. 2015 and Younes et al. 2015) and biocompatible linear polysaccharide composed of randomly distributed $\beta$-(1-4)-linked D-glucosamine and N-acetyl-D-glucosamine (Sakthivel et al. 2015 and Itoh et al. 2005). It is natural biopolymer that widely used in the field of drug delivery, as gene therapy vectors, and as polymer-protein conjugates. Also, it demonstrated antinflammatory, antiallergic, antifungal, antimicrobial, and antitumor activities (Beek et al. 2005 and Pelegri-O'Day et al. 2014). This large area of applications of chitosan is likely to be pursued further by continues modification to produce various useful hydrogels for the above mentioned applications. In particular, the reaction of chitosan with inorganic nanoparticles such as zinc was significantly improved their importance as a biochemical, analytical, antimicrobial, and anticancer agent. Whereas, the nanoparticles zinc metals are the mainly commonly studied due to their attention in the fundamental study. Also, their applied aspects such as in solar-energy conversion, luminescence, photo catalysis, electrostatic dissipative coating, transparent UV protection films, and chemical sensors (Caglar et al. 2016 and Ding et al. 2014). Furthermore, it was recognized that zinc is helpful to decrease the cardio- and hepatotoxicity induced by some anticancer drugs (Zhaoa et al. 2015 and Ding et al. 2009). Here in, we record a novel approach for preparation of different concentrations of zinc/chitosan nanocomposite based on the preferential dissociation of metal to metal ion in an aqueous solution and possible binding of these ions with active functional groups of chitosan forming complexes by electrochemical methods. These complexes when reduced will form a well dispersed nano zinc particle embedded in chitosan matrix, similar approach has been done for preparing silver and copper complexes nanocomposites (ELmezayyen and Reich 2015;
Reicha et al. 2012a and Reicha et al. 2012b).

The aim of our study was the use of nanotechnology of zinc nanoparticles with natural polymer's substance (chitosan) to reduce the hazard and spread of dangerous bacterial pathogens. It's disclosed that, nanoparticles of metals interacting with cellular components and biomicromolecules, including DNA and RNA alter cellular processes. From the point of view of antimicrobial activity, the metal nanoparticles at nano molar concentrations exhibit the excellent results in the inhibition of the bacterial strains.

\section{Experimental}

\section{Materials}

Commercially chitosan powder, from shrimp shells, with a degree of D- acetylation more than $85 \%$ were purchased from Sigma-Aldrich (St. Louis, Germany). The Zn plate purity $99.99 \%$ (1.0 $\mathrm{mm} \times 1.0 \mathrm{~mm} \times 0.2 \mathrm{~mm}$ ) was well polished before use with the aid of a very fine emery paper, cleaned by acetone ethanol $(90 \%)$ and deionized water, and used as working electrode (anode). Platinum rectangular sheet $(1.5 \mathrm{~mm} \times 1.5 \mathrm{~mm} \times 0.2 \mathrm{~mm})$ was well cleaned before use as the counter electrodes (cathode). Acetic acid of analytical grade, platinum sheet, and zinc plate were provided by Sigma Aldrich. All other reagents were of analytical grade and used as received. Deionized water (resistivity $>$ $2 \times 10^{8} \Omega \mathrm{cm}$ ) was used for all samples preparation.

Preparation of Chitosan zinc nanocomposites (CsZn NPs)

The present study was devoted to investigate the green synthesis of long-lived Cs-Zn NPs via the electrochemical oxidation of $\mathrm{Zn}$ metal into $\mathrm{Zn}^{2+}$ with in situ complexations with the chitosan, followed by reduction method using UV-irradiation as reducing agent. The electrochemical process was carried out using a potentiostatic method in a one compartment electrochemical cell at a constant potential of $1.5 \mathrm{~V}$. The used cell consists of $5 \mathrm{~cm}$ separated $\mathrm{Zn}$ (anode) and platinum (cathode) plates. The two electrodes were immersed vertically in the electrolytic solution through platinum wires, which sealed to a glass tube. The electrical contact was made via a small mercury 
pool on the enclosed end of the electrodes and connected to a suitable variable resistor, Picometer (Keithly 485), voltmeter (Keithly 175) and potential power supply (ECOS). The electrolytic solution was prepared by dissolving 1 gram of chitosan into $100 \mathrm{ml} \mathrm{1 \%}$ acetic acid solution with stirring overnight until complete dissolution and to remove any bubbles, nitrogen gas was flushed into the electrolyte during all the preparation process. The temperature was held constant at $60^{\circ} \mathrm{C}$ with the aid of a circular water bath (VEB MLW, Type U4; GDR). A thermocouple (WHEATON650 K Type) with an accuracy $\pm 0.1^{0}$ was immersed into the solution to measure its temperature. The electrolytic cell and all other detachable parts of the apparatus were cleaned, before use, with chromic acid mixture and thoroughly washed several times with distilled water and finally with deionized water. The zinc strips were first polished with a fine grade Emery paper (G400) in order to obtain a smooth surface then immersed in $\mathrm{HCl}$ acid and rinsed with deionized water. The electrochemical process was carried out for different intervals $(2,4$, $6,10,12,14,16,18 \mathrm{hr}$ ). At the end of the electrochemical process, the solution was centrifuged at speed ( $8000 \mathrm{rpm}$ for $45 \mathrm{~min}$ ) and filtered to remove any debris (metal particles in the solution). Afterward, a reduction process was performed for the resulting chitosan-Zn complexes into Cs-Zn NPs via UV irradiation with the aid of UV-lamp at $\lambda \max =254 \mathrm{~nm}$ at $25^{\circ} \mathrm{C}$ with a constant stirring for different irradiation times $(4 \mathrm{~h}$, $8 \mathrm{~h}$, and $12 \mathrm{~h}$ ).

\section{Instrumental Analyses}

Atomic absorption spectrometry was recorded for the prepared samples by Buck Scientific ACCUSYS 214USA at $\lambda=213.9 \mathrm{~nm}$, current $=2$ $\mathrm{mA}$, slit $=0.7$ and detection limit $(\mathrm{dl})$ of $0.005 \mathrm{mg} / \mathrm{l}$ using air-acetylene flame method with lean blue flame to measure the $\mathrm{Zn}$ content in the obtained chitosan-Zn complexes. The UV-Visible spectra of the chitosan-Zn complexes and NPs were recorded in the range of 200-900 $\mathrm{nm}$ using ATI Unicom UV-Vis spectrophotometer with the aid of ATI Unicom UV-Vis vision software V 3.20. The analysis was performed at room temperature using quartz cuvettes ( $1 \mathrm{~cm}$ optical path), and the blank was the corresponding chitosan aqueous solution. FTIR spectra were recorded at $25{ }^{\circ} \mathrm{C}$ using a
Mattson 5000 FTIR spectrometer in the range of $400-4000 \mathrm{~cm}^{-1}$ at a resolution of $8 \mathrm{~cm}^{-1}$. The solvent was completely pumped out at a temperature of $50{ }^{\circ} \mathrm{C}$. Then, the disks were placed in the sample holder of the spectrometer. The morphology of the resulting Cs-Zn NPs were investigated by HTEM (JEOL TEM-2100) attached to a CCD camera at an accelerating voltage of 160 $\mathrm{kV}$. The samples were prepared by placing few drops of the NPs suspension on carbon coated copper grids, followed by allowing the solvent to slowly evaporate overnight at room temperature and under vacuum before recording the TEM images, X-ray diffraction (XRD) was performed using Siemens D5000 powder diffractometer with $\mathrm{Cu} \mathrm{K} \alpha$ Radiation (wavelength $\lambda=0.15406 \mathrm{~nm}$ ) nickel filter at $40 \mathrm{kV}$ and $30 \mathrm{~mA}$. The diffractometer was operated within range of $5^{\circ}<$ $2 \theta<60^{\circ}$ with one second step-time and 0.02 degree step-size. A wider diffractometer angle ranging up to $90^{\circ}$ was tested, but no further new phases were detected so that the XRD analysis was further performed until $60^{\circ}$. Diffraction signal intensity throughout the scan was monitored and processed with DIFFRAC plus software. Topas 2.1 Profile fit software was used to extract the peak parameters using Pseudo Voigt function to model the peak shape. The XRD patterns of the synthesized samples were compared with ICDD (JCPDS) standard cards. Zinc oxide (79-2205) hexagonal phase with space grouped P63mc (186) and Zn (655973) hexagonal phase with space group P63/mmc (194).

\section{Results and discussion}

The proposed mechanism for the formation of chitosan encapsulated $\mathrm{Zn}$ composite is mainly undergone according to the following processes:

\section{Chitosan zinc complexes}

The first step was the formation of chitosan zinc complex with different molar ratios in acetic acid solution, where pure zinc metal at the anode dissociated in acetic acid solution and changed into zinc ions $\left(\mathrm{Zn}^{2+}\right)$. The $\mathrm{Zn}^{2+}$ cations immediately formed coordination bonds with $-\mathrm{OH}$ and $-\mathrm{NH}_{2}$ groups of CS chains. Two types of chelation can be occurred, they are pendant and bridged forms. We 
believed they form simultaneously, while others recorded that pendant form formed at $\mathrm{pH}<5.2$ and bridged one at higher $\mathrm{pH}$ values (Wang et al. 2004; Rhazi et al. 2002 and Hadi 2012). The amount of zinc molar ratios were monitored at the above mentioned complexation times. It showed an increase of zinc content by increasing the complexation time. This behavior is shown in Figure 1 and represented by the expositional empirical formula:

$$
\mathrm{C}=\mathrm{C}_{0}-\mathrm{A} \mathrm{B}^{\mathrm{T}}
$$

Where $\mathrm{C}$ is the concentration at any time $\mathrm{T}$ and $\mathrm{C}_{0}$ is the maximum concentration, $\mathrm{A}$ is constant= 8.14 and $\mathrm{B}$ is constant $=0.86$.

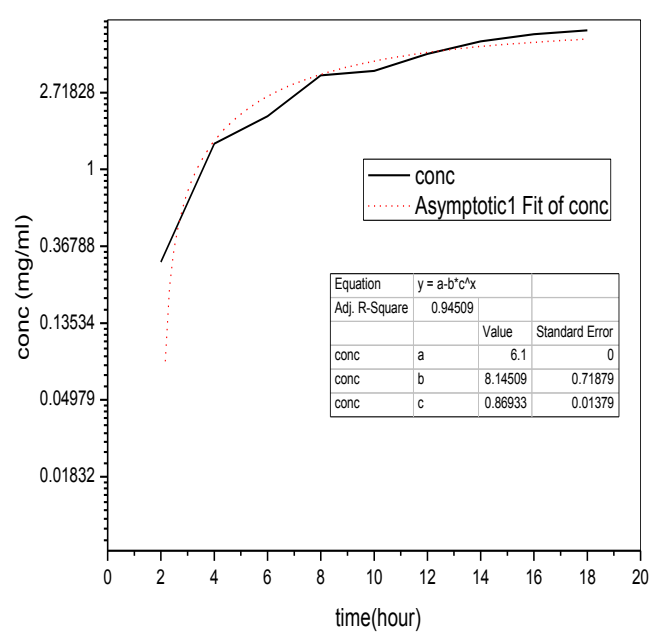

Fig. 1 Zinc content in chitosan solution.

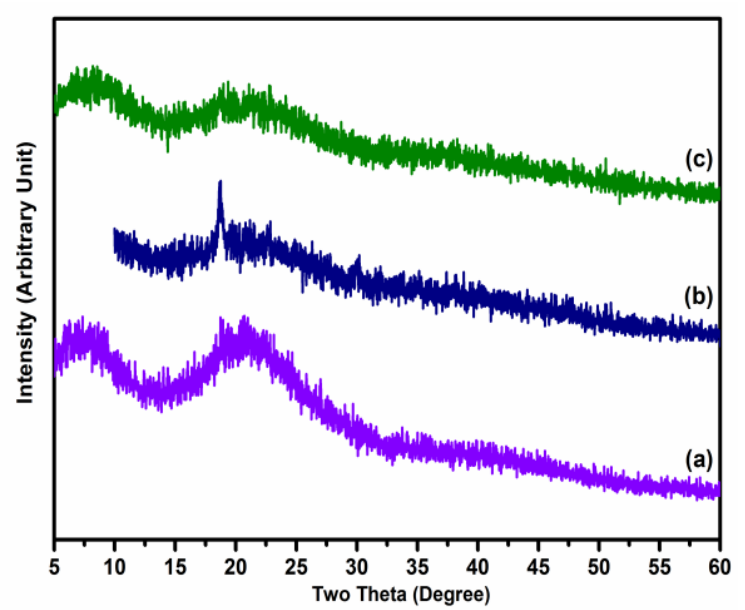

Fig. 2 XRD patterns of (a) pure chitosan, (b) complexation time $10 \mathrm{~h}$ and (c) complexation time $16 \mathrm{~h}$.
Figure 2 shows the X-ray powder diffraction patterns of the as-synthesized chitosan complex at duration time 10 and $16 \mathrm{~h}$. The XRD of chitosan is characteristic as an amorphous polymer. Two very broad peaks were observed through the diffraction pattern one from $5^{\circ}$ to $12^{\circ}$ and the other from $15^{\circ}$ to $27^{\circ}$, related to nano-chitosan. Complex after $10 \mathrm{~h}$ shows a sharp peak at $2 \theta=18.67$ degree, which could be due to crystalline chitosan not contributed in the complexation process. The pattern convenient to the study of Muzzarelli, Ferrero and Pizzoli (Muzzarelli et al. 1972). While complexes at complexation time 16 and $18 \mathrm{hr}$ showed complete amorphous phase. These results congruous with many references reported that chitosan salts form essentially amorphous phase due to chelation of metal ion with $\mathrm{NH}_{2}$ and $\mathrm{OH}$ groups. This chelation leads to break the interred molecular forces between the hydrogen bonds of $\mathrm{NH}_{2}$ and hydroxyl groups (i.e. destroy the lattice structure).

One of the most important applications of UVVis techniques is the characterization of interactions between chitosan and its solvents or dopants. Pure chitosan shows two characteristic absorptions at circa 210 and $260 \mathrm{~nm}$ revealing the presence of pure chitosan (Klung and Alexander 1974). The formation of the water-soluble [Zn (CS) $]^{+}$complex was show in Figure 3 with the help of the UV-Vis spectra of the samples through presence of absorption sharp peaks, represents UV spectra of sample prepared at duration time $6 \mathrm{~h}$, as an example, at about 256 and $326 \mathrm{~nm}$ two absorption peaks are exhibited. The peak at $256 \mathrm{~nm}$ revealed complexation of chitosan with zinc ion to form protonated $[\mathrm{CS}-\mathrm{Zn}]^{2+}$, and at $326 \mathrm{~nm}$ has been attributed to zinc nanoparticles through the complexation process. Formation of zinc nanoparticles can be attributed to the presence of zinc ions and chitosan in the same solution. Chitosan itself has two properties reducing agent and capping which prerequisite for nanoparticle formation. The FTIR experiment of the fabricated chitosan zinc complexes at time 10 and $16 \mathrm{~h}$ is represented in Figure 4 . The peaks at $1625 \mathrm{~cm}^{-1}$ which related to the $\mathrm{C}=\mathrm{O}$ stretching vibration and $1024 \mathrm{~cm}^{-1}$ corresponds to the $\mathrm{C}-\mathrm{O}$ stretching mode has been disappeared as complete complexation took place. These are well confirmed UV and Xray results. 


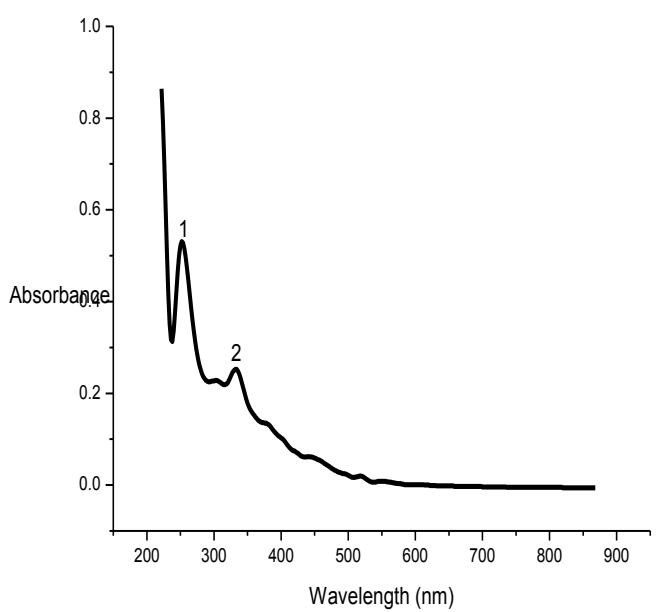

Fig. 3 UV-Vis spectra for chitosan-zinc complex prepared at duration time $6 \mathrm{~h}$.

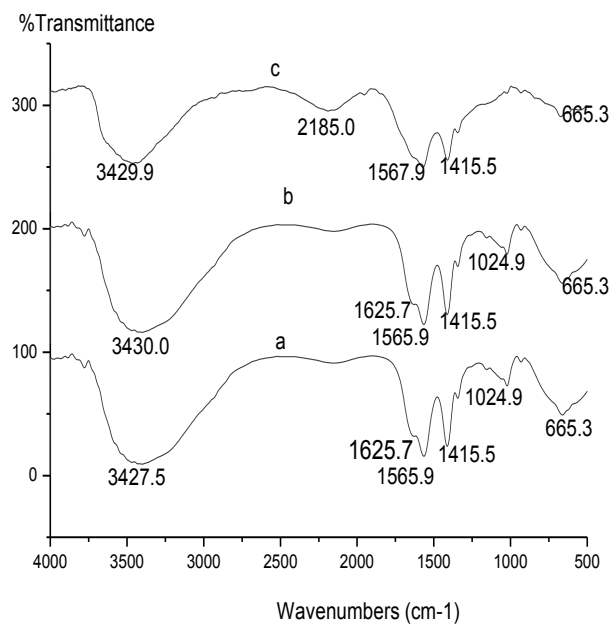

Fig. 4 FTIR spectra (a) chitosan, (b) chitosan-Zn complex $10 \mathrm{~h}$, (c) chitosan-Zn complex $16 \mathrm{~h}$.

\section{Chitosan composite}

Chitosan zinc protonated complexes produced from complexation processes were reduced by UV radiation at times $4,8,12 \mathrm{~h}$. The UV-Vis spectra of these samples are represented in Figure 5 exposed peaks at around $256 \mathrm{~nm}$ represent complex, at around $270 \mathrm{~nm}$ represent $\mathrm{ZnO} \mathrm{Nps}$ and around 330 $\mathrm{nm}$ refer to $\mathrm{Zn}$ nanoparticles. The intensity of these peaks increased by increase the concentration. In general the formed $\mathrm{Zn}$ atoms in the $[\mathrm{Zn}(\mathrm{CS})]^{\circ}$, resulting from the irradiation reduction, aggregates through metallic bonding to form the $\mathrm{Zn}$ core of the nanoparticles. The absorption spectrum of zinc nanoparticles showed duel peaks due to the secondary harmonic generation. The occurrence of duel peaks may be due to the surface dipole and quadruple plasmon resonances (Prodan et al. 2003).
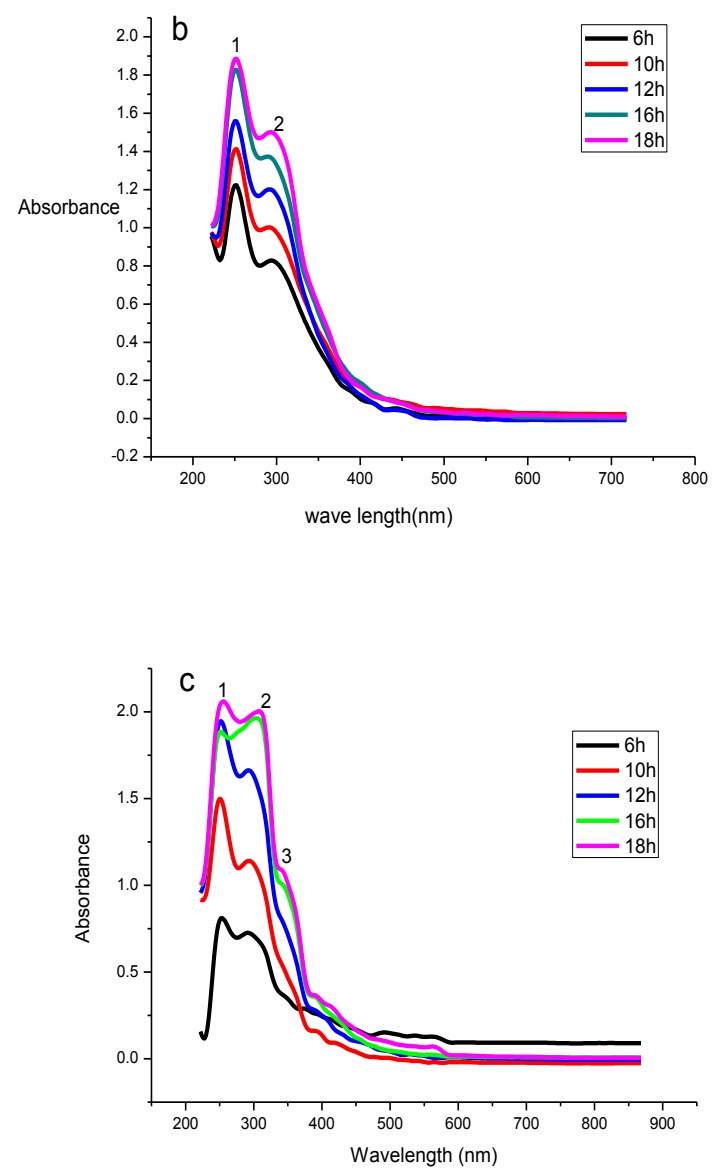

Fig. 5 Optical absorption spectra of chitosan zinc samples prepared at different complexation times and using irradiation reduction time $4 \mathrm{~h} \mathrm{(a),} 8 \mathrm{~h}$ (b) and $12 \mathrm{~h}$ (c).

Figure 6 shows XRD patterns after $12 \mathrm{~h}$ UV irradiation reduction of samples synthesized at complexation times 10 and $16 \mathrm{~h}$ where sharp peaks were observed. The Scherrer's formula estimates the average crystallite size (d) from the measured width (B) of their diffraction pattern as:

$$
\boldsymbol{d}=\frac{\boldsymbol{k} \lambda}{B \cos \theta}
$$

Where $\mathrm{k}$ is the shape coefficient (value between 
0.9 and 1.0$), \lambda$ is the $\mathrm{X}$-ray wavelength $(\lambda$ $\approx 0.154056 \mathrm{~nm}$ ). The width $\mathrm{B}$ is usually measured, in radians, at an intensity equal to half the maximum intensity, and this measure of width is termed the full-width at half the maximum (FWHM).

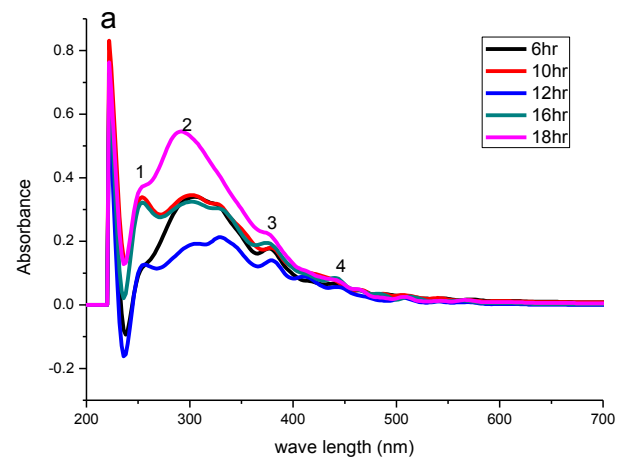

Fig. 6 XRD patterns of (a) synthesized chitosan, (b) complexation time $10 \mathrm{~h}$ and (c) complexation time $16 \mathrm{~h}$, compared with standard cards of $\mathrm{Zn}$ and $\mathrm{ZnO}$.

Table 1. FTIR of chitosan, chitosan complexes at duration time $10 \mathrm{~h}$ and $16 \mathrm{~h}$

\begin{tabular}{|c|c|c|}
\hline \multicolumn{3}{|c|}{${\text { Wavenumber }\left(\mathrm{cm}^{-1}\right)}^{-1}$} \\
\hline $\begin{array}{c}\text { Detected } \\
\text { peak of } \\
\text { Chitosan }\end{array}$ & $\begin{array}{c}\text { Detected peak of } \\
\text { complex (10 h } \\
\text { duration time) }\end{array}$ & $\begin{array}{c}\text { Detected peak } \\
\text { of complex }(16 \\
\text { h duration time })\end{array}$ \\
\hline 3426 & 3457 & 3460 \\
\hline 2924 & 3400 & 3432 \\
\hline 2101 & 2160 & 3934 \\
\hline 1647 & 1565 & 2188 \\
\hline 1563 & 1413 & 1953 \\
\hline 1413 & 1344 & 1571 \\
\hline 1382 & 1155 & 1411 \\
\hline 1318 & 1022 & 1344 \\
\hline 1258 & 931 & 672 \\
\hline 1155 & 661 & 548 \\
\hline 1072 & ------ & 496 \\
\hline 1031 & ----- & ------ \\
\hline 900 & ------ & ----- \\
\hline 702 & ----- & ---- \\
\hline 651 & & \\
\hline 618 & & \\
\hline 574 & & \\
\hline 517 & & \\
\hline
\end{tabular}

The $\mathrm{B}$ parameter was corrected using the following equation;

$$
B=\sqrt{B_{\text {Exp. }}^{2}-B_{\text {Inst }}^{2}}
$$

Where $B_{\text {Inst. }}$ corresponds to instrumental width and $B_{E x p}$. corresponds to experimental FWHM obtained for each sample. The average crystallite size of the 10 and $16 \mathrm{~h}$ UV treated chitosan were 103.5 and $116.4 \mathrm{~nm}$, respectively. The area under the diffracted peaks could be taken as an indicator for the degree of crystallinity where the crystallinity increased after 10 and $16 \mathrm{~h}$ of UV reduction. The size and morphology of zinc and zinc oxide chitosan nanocomposite rummaged by TEM is represented in Figure 7. Based on the results of the electron microscopic permission, it is experimentally shown that different nanoparticles were actually formed.

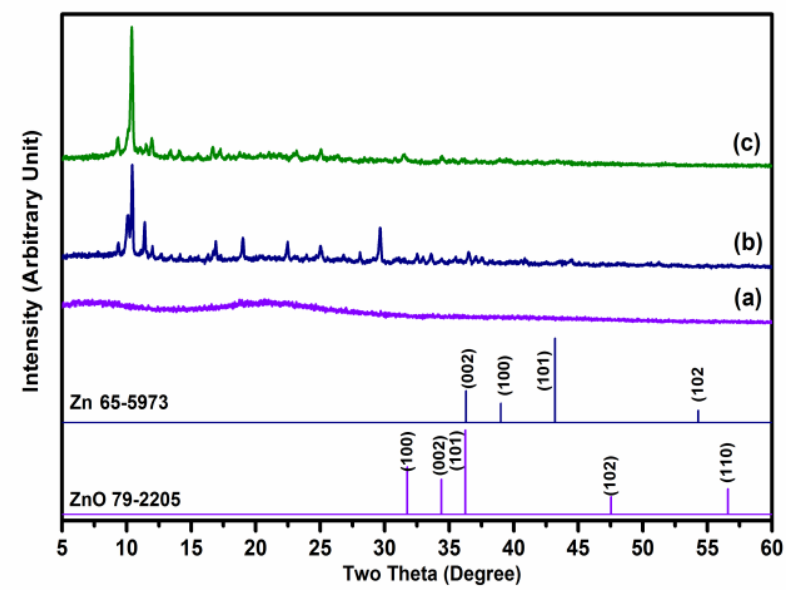

Fig 7 TEM of chitosan- zinc nanocompsite (a) bright field image, (b) electron diffraction, (c) bright field of single crystal, (d) dark field ,(e) bright field, (f) dark field

The qualitative determination of size nanoparticles confirmed well with the XRD results. Selected area electron diffraction and dark field images revealed (110) orientation. Dark field images of the formed nanoparticles showed crystals without deficits. IR -spectra of composites prepared by reducing the formed 10 and $16 \mathrm{~h}$ complexes is represented in Table 1. It is clearly seen variation in the peaks position and appearance of new peaks which confirm formation of nano hybrid composite. It is convenient to note that the 
particles thus produced in the solution remain in colloidal form for several months. It is convenient to note that the particles thus produced in the solution remain in colloidal form for several months.

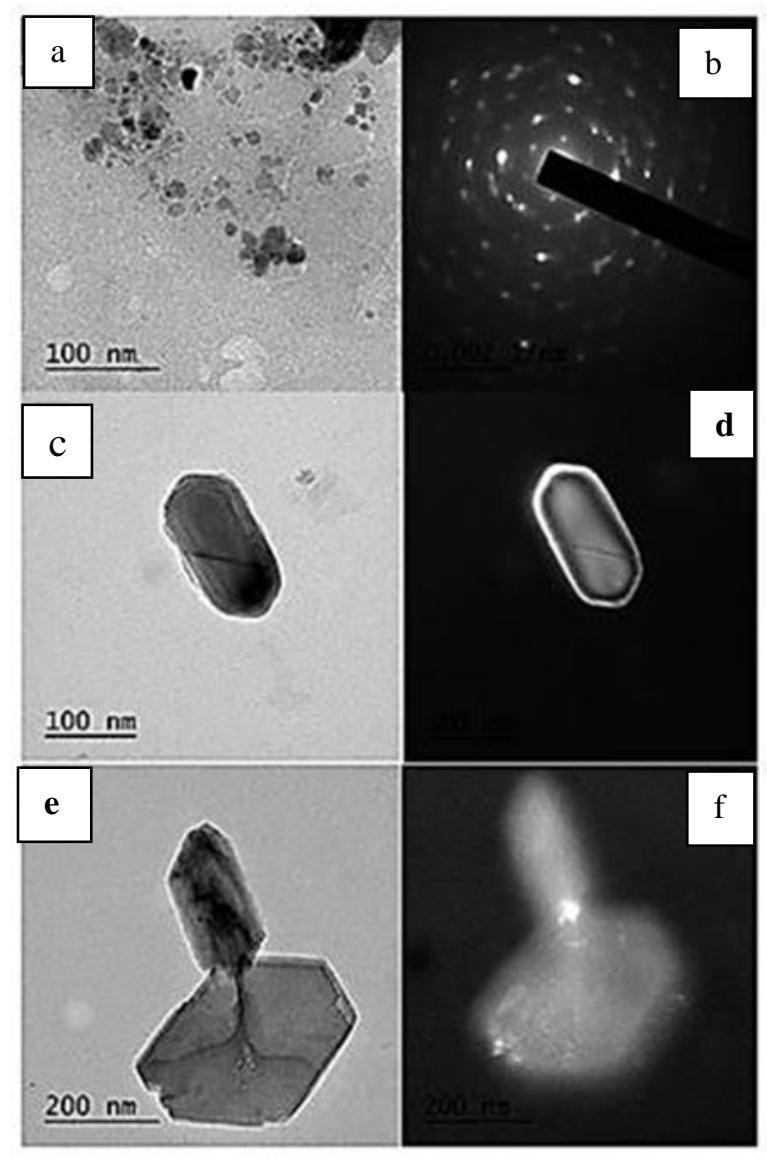

Fig. 7 TEM of chitosan- zinc nanocompsite (a) bright field image, (b) electron diffraction, (c) bright field of single crystal, (d) dark field,(e) bright field, (f) dark field

\section{References}

Aillona K.L., Xiea Y., El-Gendya N., Berklanda C.J., Forrest M.L., Res.Gate 61 (2009) 457.

Alhadlaq H.A., Akhtar M.J., Ahamed M., Cell Biosci. 5 (2015) 55.

Beek W.J.E., Wienk M.M., Kemerink M., Yang L., Janssen R.A.J., J. Phys. Chem. 109 (2005) 9505.

Caglar O., Carroy P., Losio P.A., Sinicco I., Science Direct 144 (2016) 55.
Ding L., Fanni L., Messerschmidt D., Zabihzadeh S., Sol. En. Matl. and Sol. Cells 128 (2014) 378.

Ding W., Lind S.E., Ionophores M., IUBMB Life 61 (2009) 1013.

ELmezayyen A S., Reich F.M., Open J. Appl. Sci. 5 (2015) 415.

Gong M., Wu J., Chen B., Zhuo R., Cheng S., J. Cancer Chemoth. 31 (2015) 5115.

Hadi A.G., Brit. J. sci. 6 (2012) 2047.

Hong H., Shi J., Yang Y., Zhang Y., Engle J.W., Nickles R. J., Wang X., W. Ca. Cancer-Targeted, Nano Letters 11 (2011) 3744.

Itoh Y., Wang X., Hinnebusch J., Preston J.F., Romeo T., J. Bactriol. 187 (2005) 328.

Jo D.H., Kim M.J.H., Geol Lee T., Kim J.H.. Nanomed: Nanotechno, Biology and Medicine 11 (2015) 1603

Klung H.P., Alexander E., John Wiley, New York 79 (1974) 553.

Li X ., Liu W., Sun L., Aifantis K. E., Yu B., Fan Y., Feng Q., Cui F., Watari F., J. Biomed. Mat. Res, 103 (2015) 2499.

Muzzarelli R.A.A., Ferrero A., Pizzoli M., Talanta 19 (1972) 1222.

Navale G.R., Late D.J., Shinde S.S., JSM Nanotechnol. Nanomed. 3 (2015) 1033.

Niki Y., Ogawa M., Makiura R., Magata Y. and Kojima C., T.J. Nano Med. 11 (2015) 2119.

Palza H., Inter .J. Mol. Sci. 16 (2015) 2099.

Pelegri-O’Day E. M., En-Wei Lin, Maynard H. D., J. Am. Chem. Soc. 136 (2014) 14323.

Prodan E., Radloff C., Halas N.J. Nordlander P., Science 302 (2003) 419.

Rahim M., Rosemal M., Haris H., J. Red. Res. App. Sci. 8 (2015) 255.

Reicha F. M., Sarhana A., Abdel-Hamid M., ElSherbiny I.M., Carbohyd. Polym. 89 (2012a) 236.

Reicha F. M., Shebl A.S., Badria F.A., El Asmy A.A., Int. J. Basic Appl. Chem. Sci. 2 (2012b) 7.

Rhazi M., Tolaimate D. J., Rinaudo A., Vottero M., Alagui P., Polymer 23 (2002) 1267.

Saegusa T., Macromol. Symp. 247 (2011) 129.

Sakthivel D., Vijayakumar N., Anandan V., Human J. Res. Article 4 (2015) 12.

Sirelkhatim, Mahmud S., Seeni A., Haida N., Nanomicro Lett. 7 (2015) 219.

Truonga N.P., Whittakera M.R., Maka C.W., Davis T.P., Ex.Opin. Drug Del. 12 (2015) 129.

Wang A.Z., Langer R., Farokhzad O.C., Ann. Rev. Med. 63 (2012) 185.

Wang X., Du Y., Liu H., China Carbohydr. Polymers 56 (2004) 21.

Younes I., Martel V., Rinaudo M., Inter. J. Biol. Macromol. 2 (2015) 646.

Zhaoa J., Guob Y., Hua J., Yub H., Zhib S., Zhanga J., Polyhedron 102 (2015) 550. 
الملخص العربى

\section{تحضير متراكبات نانو كيتوزان-زنك بطريقة كهروكيمائية}

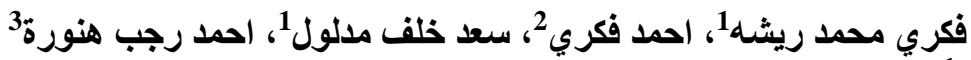

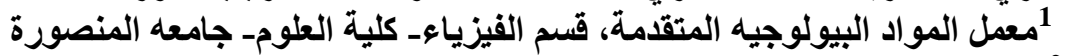

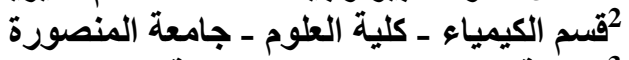

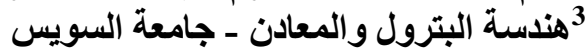

تم تحضير مركبات من بوليمرات الكيتوزان والزتك بطريقة الأكسدة الكهروكيميائية وذلك بإستخدام معدن

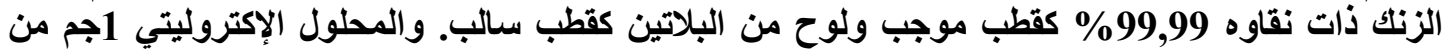

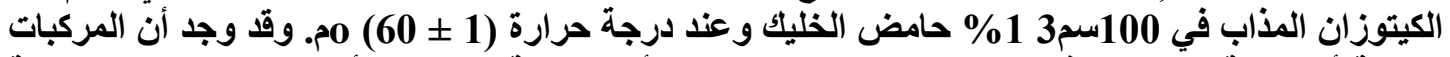

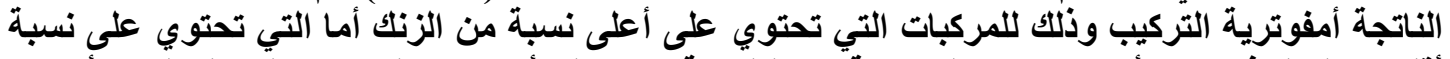

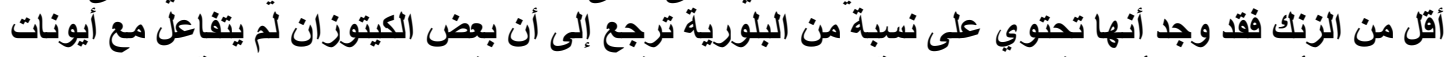

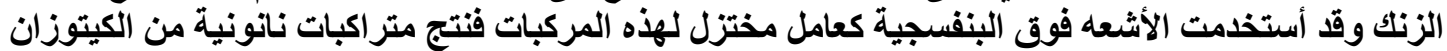

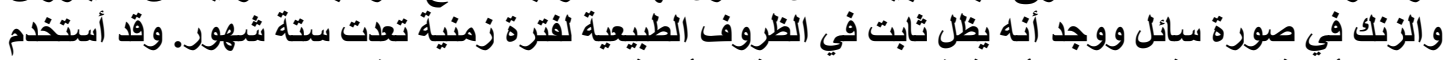

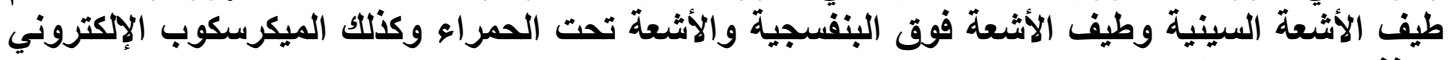
النافذ (TEM) لإثبات التركيب البنائي لتتلك المتراكبات. 